\title{
PERBEDAAN PENGETAHUAN IBU HAMIL TRIMESTER I SETELAH DIBERIKAN SELF MANAGEMENT EDUCATION MENGHADAPI EMESIS GRAVIDARUM DI BPM WILAYAH KERJA PUSKESMAS IV DENPASAR SELATAN
}

\author{
DIFFERENCES KNOWLEDGE OF PREGNANT \\ WOMEN IN FIRST TRIMESTER AFTER BEING \\ GIVEN SELF MANAGEMENT EDUCATION FACING \\ EMESIS GRAVIDARUM AT PRIVATE PRACTICE \\ MIDWIVES PUSKESMAS IV DENPASAR SELATAN
}

\author{
Ni Nyoman Deni Witari ${ }^{1}$, Ni Made Dewianti ${ }^{1}$ \\ ${ }^{1}$ Diploma III Kebidanan Politeknik Kesehatan Kartini Bali \\ dewianti1987@gmail.com
}

\begin{abstract}
Nausea, vomiting is one of the earliest, most common and most stressful symptoms in early pregnancy. Non-pharmacological therapy is a type of complementary therapy that can be used as an intervention to treat nausea. Emesis gravidarum's self management education adopts the concept of Corbin and Straus in Kate and Halsted, which is set forth in the form of a module that aims to enable pregnant women to educate themselves so as to be able to regulate their own lives, set goals, and provide self-reinforcement in dealing with nausea vomiting experienced. The purpose of this study was to determine differences in knowledge after self management education in dealing with emesis gravidarum. This research is an analytic study with a pre-experimental research design (quasi experiment design) with one group pre-test-post-test design. This research will be conducted at BPM Puskesmas IV Denpasar Selatan Work Area. The population of this study was pregnant women who came to BPM in the work area of Puskesmas IV South Denpasar. The sample of this study was pregnant women who experienced nausea and vomiting in the first trimester who met the inclusion criteria where the sampling technique in this study was accidental sampling. Bivariate analysis will be conducted t test Test to test the differences between the two pre and post test distributions before given self management education and after giving self management education to face emesis gravidarum. the average knowledge before being given the self management module was 59.1, the standard deviation value was 10.856, the minimum and maximum values were 33-87. The average value of knowledge after being given a self management module is 73.6, the standard deviation value is 13.874 with minimum and maximum values of 47-100
\end{abstract}

Keyword : Knowledge, pregnant women In First Trimester, Vomiting nausea

Balimedikajurnal.com 
BMJ. Vol 6 No 2, 2019: 198-204

ISSN : 2615-7047

DOI: https://doi.org/10.36376/bmj.v6i2

\begin{abstract}
ABSTRAK
Mual muntah adalah salah satu gejala paling awal, paling umum dan paling menyebabkan stress pada awal kehamilan. Terapi nonfarmakologi merupakan jenis terapi komplementer yang dapat digunakan sebagai intervensi untuk mengatasi mual. Self management education emesis gravidarum mengadopsi konsep dari Corbin dan Straus dalam Kate dan Halsted (2003) tersebut, yang dituangkan dalam bentuk modul yang bertujuan agar ibu hamil dapat mengedukasi diri sendiri sehingga mampu untuk mengatur hidup sendiri, mengatur tujuan, dan menyediakan penguat untuk diri sendiri dalam menangani mual muntah yang dialami.Tujuan penelitian ini adalah untuk mengetahui perbedaan pengetahuan setelah self management education menghadapi emesis gravidarum. Penelitian ini penelitian analitik dengan desain penelitian pre eksperimen (quasi experiment design) dengan rancangan one group pre test - post test design. Penelitian ini akan dilakukan di BPM Wilayah Kerja Puskesmas IV Denpasar Selatan . Populasi penelitian ini ibu hamil yang datang ke BPM wilayah kerja puskesmas IV Denpasar Selatan. Sampel penelitian ini ibu hamil yang mengalami mual muntah pada trimester I yang memenuhi kriteria inklusi dimana tehnik sampling pada penelitian ini acidental sampling . Analisa Bivariat akan dilakukan uji $t$ Test untuk menguji perbedaan dua distribusi pre dan post test sebelum diberikan self management education dan setelah pemberian self management education menghadapi emesis gravidarum. rata-rata pengetahuan sebelum diberikan modul self management adalah 59,1, nilai standar deviasi 10,856 , nilai minimum dan maksimum 33-87. Nilai rata-rata pengetahuan setelah diberikan modul self management adalah 73,6, nilai standar deviasi 13,874 dengan nilai minimum dan maksimum 47-100
\end{abstract}

Katakunci : Pengetahuan, Ibu hamil Trimester I, Mual Muntah

\author{
Alamat Korespondensi : J1. Piranha No. 2, Sesetan, Denpasar Selatan \\ Email : dewianti1987@gmail.com
}

\title{
PENDAHULUAN
}

Proses kehamilan menimbulkan berbagai perubahan pada seluruh sistem tubuh seperti kardiovaskuler, sistem pernafasan maupun gastrointestinal dipengaruhi hormon kehamilan HCG (Hormon Chorionic Gonadotropin ) (Hani, dkk, 2012)

Adaptasi fisiologis pada sistem gastrointestinal menimbulkan ketidaknyamanan berupa mual dan muntah. Ibu hamil yang mengalami mual muntah akan mengalami gangguan pada aktivitasnya. Secara psikologis, mual dan muntah selama kehamilan mempengaruhi lebih dari $80 \%$ wanita hamil serta menimbulkan efek yang signifikan terhadap quality of life (Hollyer et al,2002

Mual dan muntah merupakan hal yang normal dalam kehamilan, sekitar 50 - $90 \%$ wanita hamil mengalami mual pada trimester pertama dan sekitar $25 \%$ wanita hamil mengalami masalah mual muntah. Mual dan muntah paling sering terjadi pada kehamilan berusia muda dari minggu ke 6 setelah hari pertama haid terakhir. Pada ibu hamil yang mengalami mual muntah $50 \%$ bisa mengatasi pada usia 14 minggu dan 90\% bisa mengatasi sampai usia 22 minggu. (Kia, Et al, 2013)

Emesis Gravidarum yang berlebihan akan menjadi hiperemesis gravidarum dapat mengganggu metabolisme tubuh ibu, dehidrasi, berat badan menurun, 
alkalosis, dan hypokalemia. Dampak pada janin seperti abortus, BBLR, kelahiran prematur, serta malforasi pada bayi baru lahir. (Runiari 2010).

Sebagaian besar ibu hamil yang mengalami mual dan muntah di masyarakat menggunakan terapi farmakologis, yaitu dengan obat-obatan atau dengan didiamkan saja. Penggunaan farmakologi untuk ibu hamil perlu diperhatikan karena terjadi perubahan farmakokinetik maupun farmakodinamik obat saat terjadi kehamilan. Terapi nonfarmakologi merupakan jenis terapi komplementer yang dapat digunakan untuk mengatasi mual : hipnoterapi, akupresur, akupuntur, relaksasi, dan terapi. (Mazzotta \& Magee, 2000)

Penanganan mual muntah pada ibu perlu dilakukan untuk meningkatkan status kesehatan ibu salah satunya dengan menciptakan perilaku untuk mengurangi keluhan. Menciptakan perilaku untuk hidup sehat sesuai kondisi pasien merupakan bagian dari self management. (Kate \& Halsted, 2003). Tujuan penelitian ini adalah untuk mengetahui perbedaan pengetahuan setelah self management education menghadapi emesis gravidarum.

\section{METODE PENELITIAN}

Penelitian ini dilaksanakan di BPM Wilayah Kerja Puskesmas Denpasar Selatan yang berjumlah enam BPM . Desain penelitian ini merupakaan penelitian dengan menggunakan pendekatan kuantitatif. Desain penelitian yang digunakan dalam penelitian ini adalah quasi experimental with one group pretest-posttest design. Dengan mengkaji pemberian self management menurunkan mual muntah pada ibu hamil. Jenis data yang dikumpulkan adalah data sekunder yang didapat dari register kunjungan ibu hamil di BPM , profil puskesmas dan data primer yang diperoleh langsung dari wawancara dengan responden tentang karakteristik, pengetahuan dan data tingkat mual muntah. Cara pengumpulan data diawali dengan permohonan ijin kepada Dinas Kesehatan Provinsi Bali serta BPM yang menjadi tempat penelitian untuk pengambilan data awal dan melakukan ijin penelitian. Instrumen yang digunakan adalah kuesioner untuk mengetahui pengetahuan, modul dan SOP self management menghadapi emesis gravidarum. Prosedur penelitian subyek penelitian yang memenuhi kriteria inklusi akan dilakukan wawancara dan diberi informed consent untuk kesediaannya memberikan informasi yang dibutuhkan dan bersedia untuk diberikan edukasi self management mengatasi mual muntah. Subyek penelitian yang sudah bersedia akan dikaji pengetahuannya tentang emesis gravidarum dan tingkat keparahan mual muntah. Populasi pada penelitian ini adalah seluruh ibu hamil yang melakukan kunjungan antenatal di BPM wilayah kerja Puskesmas IV Denpasar Selatan tahun 2018. Sampel penelitian ini yaitu ibu hamil yang mengalami mual dan muntah yang berkunjung ke BPM Wilayah Kerja Puskesmas IV Denpasar Selatan yang memenuhi kriteria inklusi penelitian. Kriteria inklusi sampel dalam penelitian ini yaitu, Ibu hamil trimester I yang mengalami mual dan muntah, bersedia menjadi responden, tidak mengalami komplikasi pada kehamilan. Kriteria eksklusi adalah Ibu hamil trimester I yang mengalami komplikasi, hyperemesis gravidarum, dan grastritis. Tehnik sampling yang digunakan adalah accidental sampling, dimana pengambilan sampel secara aksidental dengan mengambil responden yang kebetulan ada atau pada saat penelitian. Penelitian ini akan dilakukan selama empat bulan di BPM Wilayah 
BMJ. Vol 6 No 2, 2019: 198-204

ISSN : 2615-7047

DOI: https://doi.org/10.36376/bmj.v6i2

Puskesmas IV Denpasar Selatan. Analisa data menggunakan Paired T-test dengan interval kepercayaan 95\% dan tingkat kemaknaan $\mathrm{P}<0,05$

HASIL DAN DISKUSI

Hasil Penelitian

Tabel 1. Distribusi Frekuensi Pengetahuan Sebelum Diberikan Modul Self Management di PMB Wilayah Kerja Puskesmas IV Denpasar Selatan Tahun 2019

\begin{tabular}{|c|c|c|c|}
\hline No. & Pengetahuan & Frekuensi (f) & Persentase (\%) \\
\hline 1 & Kurang & 16 & 40 \\
\hline 2. & Cukup & 21 & 52,5 \\
\hline 3. & Baik & 3 & 7,5 \\
\hline \multicolumn{2}{|r|}{ Total } & 40 & 100 \\
\hline
\end{tabular}

Sumber: Data Primer Penelitian Tahun 2019

Berdasarkan tabel 1 menunjukkan bahwa dari 40 responden sebelum diberikan modul self management yaitu sebagian kecil 3 responden $(7,5 \%)$ memiliki pengetahuan baik, hampir setengah 16 responden $(40 \%)$ memeiliki pengetahuan cukup, dan lebih dari setengahnya 21 responden $(52,5 \%)$ memiliki pengetahuan baik.

Tabel 2 Distribusi Frekuensi Pengetahuan Sesudah Diberikan Modul Self Management di PMB Wilayah Kerja Puskesmas IV Denpasar Selatan Tahun 2019

\begin{tabular}{cccc}
\hline No. & Pengetahuan & Frekuensi (f) & Persentase (\%) \\
\hline 1 & Kurang & 4 & 10 \\
2. & Cukup & 21 & 52,5 \\
3. & Baik & 15 & 37,5 \\
\hline \multicolumn{2}{c}{ Total } & 40 & 100 \\
\hline
\end{tabular}

Berdasarkan tabel 2 menunjukkan bahwa dari 40 responden setelah diberikan modul self management yaitu sebagian kecil 4 responden (10\%) memiliki pengetahuan kurang, hampir setengah 15 responden $(37,5 \%)$, lebih dari setengahnya 21 responden $(52,5 \%)$ memiliki pengetahuan cukup. 
BMJ. Vol 6 No 2, 2019: 198-204

ISSN : 2615-7047

DOI: https://doi.org/10.36376/bmj.v6i2

Tabel 3 Pengetahuan Sebelum dan Sesudah Diberikan Modul Self Management di PMB Wilayah Kerja Puskesmas IV Denpasar Selatan Tahun 2019

\begin{tabular}{ccccc}
\hline Variabel & Mean & SD & Minimum & Maksimum \\
\hline Pre test & 59,1 & 10,856 & 33 & 87 \\
\hline Post test & 73,6 & 13,874 & 47 & 100 \\
\hline
\end{tabular}

Berdasarkan tabel 3 rata-rata pengetahuan sebelum diberikan modul self management adalah 59,1, nilai standar deviasi 10,856, nilai minimum dan maksimum 33-87. Nilai rata-rata pengetahuan setelah diberikan modul self management adalah 73,6 , nilai standar deviasi 13,874 dengan nilai minimum dan maksimum 47-100

Tabel 4 Wilcoxon Signed Ranks Test

\begin{tabular}{llrrr}
\multicolumn{5}{c}{ Ranks } \\
\hline & $\mathrm{N}$ & Mean Rank & Sum of Ranks \\
Post_Pengetahuan & Negative Ranks & $0^{\mathrm{a}}$ & .00 & .00 \\
Pre_Pengetahuan & Positive Ranks & $34^{\mathrm{b}}$ & 17.50 & 595.00 \\
& Ties & $6^{\mathrm{c}}$ & & \\
& Total & 40 & & \\
\hline
\end{tabular}

a. Post_Pengetahuan < Pre_Pengetahuan

b. Post_Pengetahuan > Pre_Pengetahuan

c. Post_Pengetahuan $=$ Pre_Pengetahuan

\begin{tabular}{lr}
\hline \multicolumn{3}{c}{ Test Statistics $^{\text {a }}$} \\
\hline \multicolumn{3}{c}{$\begin{array}{r}\text { Post_Pengetahua } \\
n-\end{array}$} \\
& Pre_Pengetahuan \\
\hline$Z$ & $-5.103^{\mathrm{b}}$ \\
\hline Asymp. Sig. (2-tailed) & .000 \\
\hline a. Wilcoxon Signed Ranks Test \\
b. Based on negative ranks.
\end{tabular}

Berdasarkan tabel 5.12 didapatkan bahwa nilai Asymp. Sig.(2-tailed) dengan tingkat kesalahan $0.5 \%$ dimana p value $(0.000)$, $(\mathrm{p}<0.05)$, sehingga Ho ditolak dan Ha diterima menyimpulkan bahwa ada pengaruh pemberian modul self management terhadap peningkatan pengetahuan untuk mengurangi mual muntah.

\section{Diskusi Hasil}

\section{Pengaruh pemberian modul terhadap peningkatan pengetahuan ibu hamil}

Penelitian ini menggunakan kuesioner untuk mengukur pengetahuan responden mengenai emesis gravidarum. Hal ini sesuai dengan teori Notoatmodjo (2012) yang menyatakan bahwa pengukuran pengetahuan dapat dilakukan dengan wawancara atau kuesioner yang menanyakan tentang isi materi yang diukur dari responden

Hasil penelitian ini menggambarkan peningkatan pengetahuan ibu hamil dari sebelum pemberian dan sesudah pemberian modul. Rerata peningkatan sebesar 
BMJ. Vol 6 No 2, 2019: 198-204

ISSN : $2615-7047$

DOI: https://doi.org/10.36376/bmj.v6i2

14,5 poin yaitu sebesar 59,1 dengan standar deviasi 10,85 sebelum perlakuan, dan 73,6 dengan standar deviasi 13,87 setelah perlakuan. Hasil analisis statistik dengan uji Wilcoxon menunjukkan sejumlah 34 reponden (85\%) mengalami peningkatan pengetahuan dengan nilai $p=0,000$. Hal ini membuktikan bahwa terdapat pengaruh yang signifikan pada pemberian self management module dalam peningkatan pengetahuan ibu hamil mengurangi mual muntah.

Pemberian modul pada ibu hamil trimester I yang tentang kehamilan, tanda-tanda perubahan kehamilan, morning sickness dan self manajement mengurangi mual muntah merupakan salah satu informasi yang sangat penting bagi ibu hamil untuk menghadapi mual muntah pada kehamilannya. Dengan informasi ini diharapkan ibu hamil mampu meningkatkan pengetahuan ibu tentang perubahan kehamilannya ,mengurangi mual muntah, mengatasi mual muntah dan mengatur aktivitasnya menjalani kehamilan dengan baik

Hal ini sesuai dengan teori bahwa pengetahuan diperoleh melalui belajar yang merupakan suatu proses mencari tahu yang tadinya tidak tahu menjadi tahu, konsep mencari tahu mencakup berbagai metode dari konsep, baik melalui proses pendidikan maupun pengalaman. Pengetahuan adalah sebagian ingatan atas bahanbahan yang telah dipelajari, mengingat kembali sekumpulan bahan yangluas dari hal-hal terperinci untuk teori tetapi apa yang diberikan telah menggunakan ingatan akan keterangan yang sesuai (Notoatmodjo, 2012).

\section{SIMPULAN DAN SARAN}

\section{Simpulan}

1. Sebelum diberikan modul self management sebagian kecil 3 responden $(7,5$ \%) memiliki pengetahuan baik

2. Setelah diberikan modul self management hampir setengah 15 responden $(37,5 \%)$

3. Ada pengaruh pemberian modul self management terhadap peningkatan pengetahuan untuk mengurangi mual muntah.

\section{Saran}

Berdasarkan penelitian yang sudah dilaksanakan, disarankan untuk petugas kesehatan dapat mengadopsi modul self management sebagai salah satu upaya untuk mengatasi mual muntah pada ibu hamil trimester I

\section{UCAPAN TERIMA KASIH}

Ucapan terima kasih penulis ucapkan kepada Ibu Ketua Yayasan Kartini Bali, Ibu Direktur Politeknik Kesehatan Kartini Bali serta semua pihak yang telah membantu dalam pelaksanaan penelitian ini.

\section{DAFTAR PUSTAKA}

1. Hani,Ummi,dkk. (2011). Asuhan Kebidanan Pada Kehamilan Fisiologis. Jakarta : Salemba Medika.

2. Hollyer et al., (2002). The use of CAM by women suffering from nausea and vomitting during pregnancy. BMC complementary and alternative medicine. 
BMJ. Vol 6 No 2, 2019: 198-204

ISSN : 2615-7047

DOI: https://doi.org/10.36376/bmj.v6i2

Diperoleh tanggal 20 Juni 2017 dari http://www.biomedical.com/14726882/2/5/prepub.

3. Kia, P.Y., Safajou, F .,Shahnazi, M. \& Nazemiyeh, H. (2013) The effect of Lemon Inhalation Aromatherapy on Nausea and Vomiting of Pregnancy : A DoubleBlinded, Randomized Contrlled Clinical Trial. Iranian Red Crescent Medical Journal. 2014 Marrch 16 (3) :e14360.

4. Runiari, Nengah.( 2010). Asuhan Keperawatan pada Klien dengan Hiperemesis gravidarum. Jakarta : Salemba Medika

5. Mazzotta, P., \& Magee, LA. (2000). A riskbenefit assessment of pharmacological and nonpharmacological treatments for nausea and vomiting of pregnancy. PubMed, 59(4), 781-800

6. Kate, R.L., \& Halsted , R.W. (2003). Self management education: History, definition, outcomes and mechanism. Ann Behav Med,1-7.

7. Notoatmodjo, S, 2012, Promosi Kesehatan dan Perilaku Kesehatan, Jakarta: Rineka Cipta 